\title{
Thermodynamic Studies of Tl-Bi Liquid Alloys
}

\author{
By Osamu Mikuni*, Mitsuo Shimoji** and Kichizo Niwa**
}

\begin{abstract}
The e.m.f. of the cell $\mathrm{Tl}(\mathrm{l}) / \mathrm{TlCl}$ in $\mathrm{KCl}-\mathrm{LiCl} / \mathrm{Ti}-\mathrm{Bi}(\mathrm{l})$ was measured over the temperature range of $370^{\circ}$ to $480^{\circ} \mathrm{C}$. The activity curve shows a profoundly negative deviation from Raoult's law. The excess thermodynamic functions were calculated from the activity data obtained. Theoretical consideration was given for the excess functions of this system. (Received August 16, 1961)
\end{abstract}

\section{Introduction}

Previous thermodynamic studies on the Tl-Bi system have been carried out mainly by means of the electromotive force (e.m.f.) method. The e.m.f of the $\mathrm{Tl} / \mathrm{Tl}^{+} /$ $\mathrm{Tl}-\mathrm{Bi}$ cell was measured by Olander ${ }^{(1)}$ with solid $\mathrm{Tl}$ and $\mathrm{Tl}-\mathrm{Bi}$ alloys $\left(120\right.$ to $165^{\circ} \mathrm{C}$, and 245 to $\left.295^{\circ} \mathrm{C}\right)$, and that of a similar cell was also measured by Engelhardt and Wagner(2) with liquid Tl-Bi against liquid and solid $\mathrm{Tl}\left(480^{\circ} \mathrm{C}\right.$ and $\left.270^{\circ} \mathrm{C}\right)$, and by Vierk ${ }^{(3)}$ with both electrodes liquid (only at $459^{\circ} \mathrm{C}$ ). Vierk used solid glass as the solvent for the electrolyte, while Engelhardt

** Department of Chemistry, Faculty of Science, Hokkaido University, Sapporo, Japan.

* Muroran Works, Fuji Seitetsu K. K., Muroran, Japan.

(1) A. Ölander: Z. Phys. Chem., (A) 169 (1934), 260.

(2) G; Engelhardt and C. Wagner: Z. Phys. Chem., (A) 159 (1932), 241.

(3) A. L. Vierk: Z, Elektrochem., 54 (1950), 436, and Wagner $\mathrm{KCl}-\mathrm{MgCl}_{2}$ at $480^{\circ} \mathrm{C}$ and $\mathrm{Na}^{+}-\mathrm{K}^{+}$-acetates at $270^{\circ} \mathrm{C}$. Acetates were also used by ölander for this purpose. There are no reliable recorded e.m.f. values of the liquid state for this system, except the limited data of the activities measured by Engelhardt and Wagner and by Vierk. According to Kubaschewski and Catterall's calculation ${ }^{(4)}$, the agreement of the calculated enthalpy of mixing based upon the above data is unsatisfactory. This may be due to the small number of experimental runs. The purpose of the present study is to measure the e.m.f. as more detailed functions of temperatures and to obtain knowledge of the activities, entropies and enthalpies of this system.

The partial molar free energy of $\mathrm{Tl}, \Delta \widetilde{G}_{\mathrm{Tl}}$, and the activity of $\mathrm{Tl}, a_{\mathrm{Tl}}$, at a temperature $\mathrm{T}$ are related to the

(4) O. Kubaschewski and J. A. Catterall : Thermochemical Data of Alloys, Pergamon Press Ltd., (1956). 
e.m.f. as follows :

$$
\Delta \bar{G}_{\mathrm{T} 1}=-n F E=R T \ln a_{\mathrm{T} 1},
$$

where $F$ is the Faraday constant. $n$, the valence of $\mathrm{Tl}$ in the salt, $E$, the e.m.f., and $R$, the gas constant. The partial molar entropy of $\mathrm{Tl}, \Delta \bar{S}_{\mathrm{Tl}}$, is calculated from the temperature coefficient:

$$
\Delta \bar{S}_{\mathrm{Tl}}=n F\left(\frac{\partial E}{\partial T}\right) .
$$

And the partial molar enthalpy of $\mathrm{Tl}, \Delta \bar{H}_{\mathrm{Tl}}$ is obtained by combining equations (1) and (2) namely Eq. (3):

$$
\Delta \bar{H}_{\mathrm{Tl}}=\Delta \bar{G}_{\mathrm{Tl}}+T \Delta \bar{S}_{\mathrm{Tl}}=-n F\left\{E-T\left(\frac{\partial E}{\partial T}\right)\right\}
$$

The partial molar quantities of Bi are evaluated by the graphical integration of the Gibbs-Duhem equation.

\section{Experimental}

The use of the e.m.f. cell method for study of alloy solutions is now a standard procedure. The details of expermental methods are the same as those described elsewhere ${ }^{(5)}$. Electrode concentration cells of the following type were operated $(n=1)$ :

Tl (liquid)/ TlCl in $\mathrm{KCl}$ - LiCl (eutectic composition)/

Tl-Bi(liquid).

The cell was assembled, sealed and evacuated to a pressure of $10^{-4} \mathrm{~mm} \mathrm{Hg}$ to degas the metals and electrolytes. The system was held at this pressure for 2 hours, thereafter purified nitrogen gas was introduced. In the present investigation, most measurements were performed over the temperature range of 370 to $480^{\circ} \mathrm{C}$. The metals used were all high-purity elements with total impurities less than $0.05 \%$. Temperature was measured by means of the calibrated alumel-chromel thermocouple, located at the center of the legs. The measured e.m.f. values were reproducible to better than $0.05 \mathrm{mV}$ for periods of 10 to 20 minutes.

\section{Results}

The results of this experiment are summarized in Table 1, and the corresponding thermodynamic quantities are presented graphically in Figs. 1 to 4. Fig. 1 shows

Table 1 e.m.f. and its temperature coefficient in TI-Bi liquid solution at $700^{\circ} \mathrm{K}$.

\begin{tabular}{l|c|c|c}
\hline$x_{\mathrm{T} 1}$ & $E(\mathrm{mV})$ & $(d E / d T) \times 10^{6}(\mathrm{~V} / \mathrm{deg})$ & $a_{\mathrm{T} 1}$ \\
\hline 0.103 & 273.0 & 195.0 & 0.011 \\
0.189 & 204.0 & 140.0 & 0.021 \\
0.255 & 191.5 & 117.0 & 0.042 \\
0.263 & 184.0 & 118.0 & 0.047 \\
0.403 & 149.0 & 73.0 & 0.085 \\
0.432 & 118.3 & 64.0 & 0.141 \\
0.526 & 91.3 & 52.0 & 0.220 \\
0.645 & 65.8 & 40.0 & 0.336 \\
0.741 & 41.9 & 28.0 & 0.499 \\
0.805 & 24.8 & 15.5 & 0.663 \\
\hline
\end{tabular}

the activities of $\mathrm{T} 1$ and $\mathrm{Bi}$ at $700^{\circ} \mathrm{K}$ along with corresponding data from the earlier e.m.f. studies of Engelhardt and Wagner $\left(751^{\circ} \mathrm{K}\right)$ and of Vierk $\left(732^{\circ} \mathrm{K}\right)$. It will be noted that there is a reasonable agreement between the authors' results and the earlier results, and that the activity curves show profoundly negative

(5) K. Niwa, M. Shimoji and O. Mikuni : J. Japan Inst. Metals, 24 (1960), 668 deviations from Raoult's law. Figs. 2 to 4 show the relative partial molar quantities of $\mathrm{Tl}$ and $\mathrm{Bi}$, and corresponding integral values at $700^{\circ} \mathrm{K}$. The excess entropies indicate slightly negative deviations from

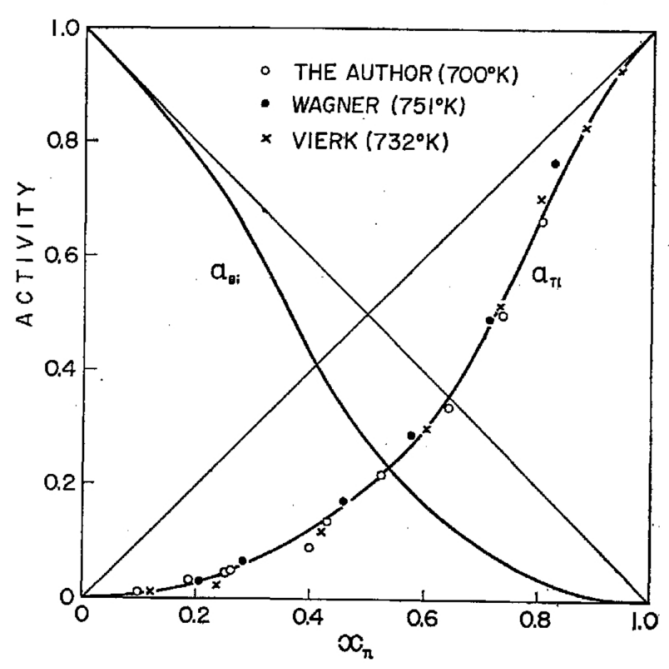

Fig. 1 Activity curves in $\mathrm{Tl}-\mathrm{Bi}$ solution.

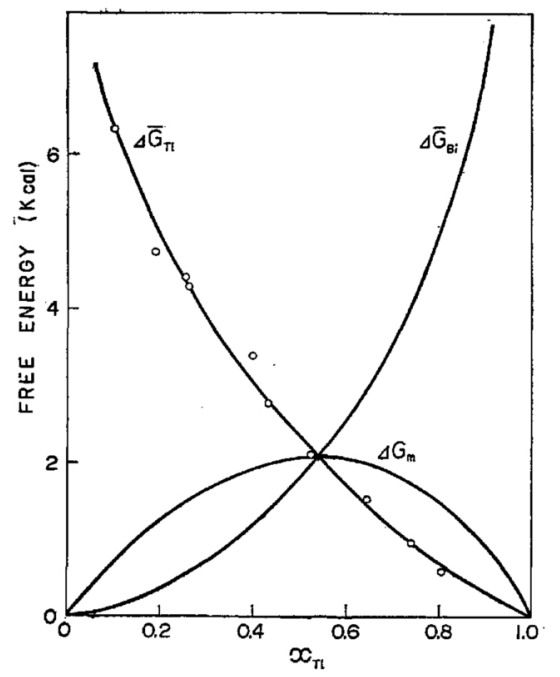

Fig. 2 Free energy of mixing and partial molar quantities at $700^{\circ} \mathrm{K}$.

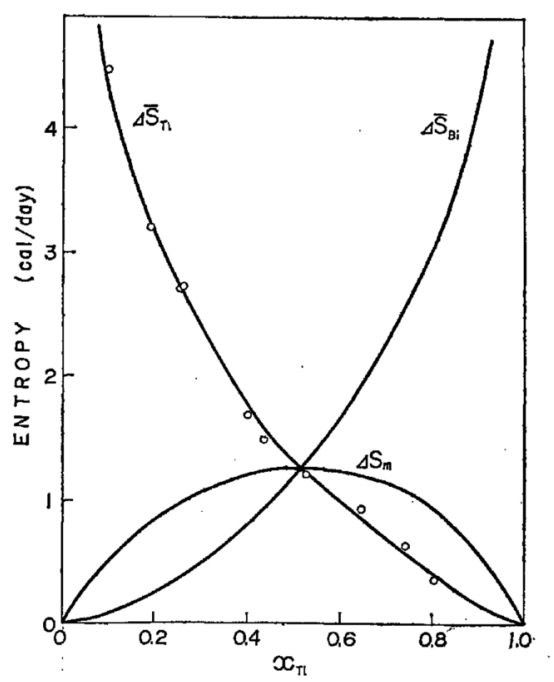

Fig. 3 Entropy of mixing.

those of the ideal solution. The excess heats and excess entropies of the Tl-Bi liquid alloys are tabulated in Table 2. 


\section{Discussion}

Kubaschewski and Catterall(4) tabulated values of entropy and enthalpy of this system by using Engelhardt and Wagner's results ${ }^{(2)}$. But the latter measured the

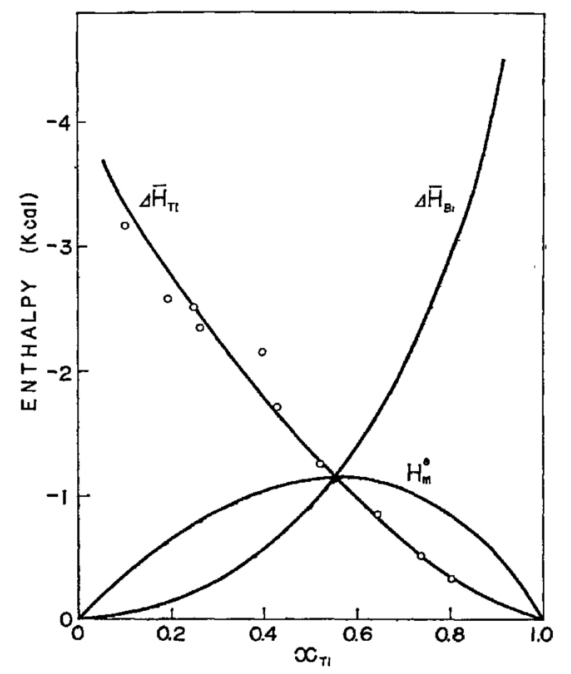

Fig. 4 Enthalpy of mixing.

Table 2 Thermodynamic values of Tl-Bi liquid alloys.

\begin{tabular}{l|c|c|c|c}
\hline \hline$x_{\mathrm{T} 1}$ & $\Delta S_{m}$ & $-S_{m}^{e}$ & $-H_{m}^{e}$ (present) & $-\Delta H_{m}$ (Wittig \& Müller) \\
\hline 0.1 & 0.59 & 0.15 & 354 & 267 \\
0.2 & 0.84 & 0.15 & 656 & 494 \\
0.3 & 1.07 & 0.13 & 885 & 703 \\
0.4 & 1.22 & 0.12 & 1050 & 888 \\
0.5 & 1.27 & 0.11 & 1136 & 1026 \\
0.6 & 1.25 & 0.09 & 1146 & 1083 \\
0.7 & 1.12 & 0.08 & 1068 & 1025 \\
0.8 & 0.93 & 0.06 & 872 & 827 \\
0.9 & 0.59 & 0.05 & 555 & 480 \\
\hline
\end{tabular}

$\Delta S_{m}$ and $S_{m}^{e}: \mathrm{cal} \cdot \mathrm{deg}^{-1} \cdot \mathrm{mole}^{-1} ; \Delta H_{m}=\boldsymbol{H}_{m}^{e}: \mathrm{cal} \cdot \mathrm{mole}^{-1}$

e.m.f at only two temperatures, $270^{\circ} \mathrm{C}$ and $480^{\circ} \mathrm{C}$. Thus the values of the former may be somèwhat unreliable in view of the difficulty of interpolating over such a wide range on the basis of the results only at those two temperatures.

Heat contents at various temperatures between $20^{\circ} \mathrm{C}$ and $500^{\circ} \mathrm{C}$ were determined by Kubaschewski ${ }^{(6)}$ for two compositions: $x_{\mathrm{T} 1}=0.333$ and 0.400 . These may be used $^{(4)}$, together with the heat contents of $\mathrm{Tl}$ and $\mathrm{Bi}^{(7)}$ and the enthalpies of mixing of Olander(1) in the solid state, to calculate the enthalpies of mixing of the corresponding liquid alloys from the liquid metals. Recently Wittig and Müller ${ }^{(8)}$ have .measured the enthalpies of mixing in this system at $350^{\circ} \mathrm{C}$ by a calorimetric method. These may be compared with the heats obtained from the e.m.f. data. Those values are tabulated in Table 3. In comparison with earlier e.m.f. data, the present e.m.f. results are very near to the heat data. The calorimetric method is more reliable for the

(6) O. Kubaschewski : Z. Elektrochem., 47 (1941), 475.

(7) K. K. Kelley: U. S. Bur. Mines, No. 476 (1949).

(8) F. E. Wittig and E. Müller: Z. Phys. Chem., 21 (1959), 47. enthalpy of mixing and the calculation for entropy of mixing is made by combining those enthalpies with the energy of mixing obtained by the e.m.f. method.

It is interesting to compare the present result with the theoretical equations for the energies of alloys. The atomic radii of Goldshmidt is $1.71 \AA$ for $\mathrm{Tl}$ and $1.82 \AA$ for $\mathrm{Bi}$, but the metallic radii are respectively $1.71 \AA$

Table 3 Enthalpy of mixing of Ti-Bi liquid alloys $\left(\mathrm{cal} \cdot \mathrm{mole}^{-1}\right.$ )

\begin{tabular}{l|l|l|l}
\hline$x_{\mathrm{T} 1}$ & 0.333 & 0.375 & 0.400 \\
by Wagner & -450 & & -540 \\
by Vierk & -115 & -135 & -155 \\
by $\Delta C_{P}$ & -690 & -925 \\
by the authors & -910 & -1000 & -1050 \\
by Wittig \& Müller & & & -1090 \\
\hline
\end{tabular}

and $1.70 . \AA^{(9)}$. In the liquid state the cohesion of $\mathrm{Bi}$ atoms may be more metallic than in the solid state. Consequently, the spheres of both metals may be regarded as having the same radii in the liquid alloys. Then the size effect may be negligible in the Tl-Bi liquid solution. The most prominent contribution to the excess enthalpy is due to the difference of electronegativities of the two metals (Tl: 1.5, Bi: 1.8) or an electron transfer.

The asymmetric behavior of the excess heats can be explained in terms of the electron transfer theory(10)(11), if the number of valence electrons is $Z_{\mathrm{Tl}}=3$ for $\mathrm{Tl}$ and $Z_{\mathrm{Bi}}=5$ for $\mathrm{Bi}$ in accordance with the positions in the periodic table. When the size effect can be neglected the electron transfer theory of metallic solution gives

$$
\left(\frac{\alpha_{\mathrm{Bi}}}{\alpha_{\mathrm{Tl}}}\right) \cong\left(\frac{Z_{\mathrm{Tl}}}{Z_{\mathrm{Bi}}}\right)^{1 / 3}
$$

Here, $\alpha_{\mathrm{Bi}}$ and $\alpha_{\mathrm{Tl}}$ are given by

$$
\lim _{x_{\mathrm{T} 1} \rightarrow 0} \Delta H_{m} / x_{\mathrm{Tl}}=\alpha_{\mathrm{Bi}} \quad \text { (in Bi side), }
$$

and

$$
\lim _{x_{\mathrm{Bi}^{-}} \rightarrow 0} \Delta H_{m} / x_{\mathrm{Bi}}=\alpha_{\mathrm{Tl}} \quad \text { (in Tl side). }
$$

The predicted relation then becomes

$$
\left(\frac{\alpha_{\mathrm{Bi}}}{\alpha_{\mathrm{T}}}\right)_{\text {theor. }} \cong\left(\frac{3}{5}\right)^{1 / 3}=0.84
$$

The observed ratio is.

$$
\left(\frac{\alpha_{\mathrm{Bi}}}{\alpha_{\mathrm{Tl}}}\right)_{\mathrm{obs} .} \cong 0.6
$$

Hence, the form of energetic asymmetry may qualitatively be explained by the electron transfer theory.

Finally, it is interesting to note that the excess entropy has a slightly negative value in the liquid alloys in spite of its positive values in the solid alloys. Probably this may be due to the reason that the covalent bonding of $\mathrm{Bi}$ atoms in the solid state disappears in the liquid state.

\footnotetext{
(9) L. Pauling: J. Amer. Chem. Soc., 69 (1947), 542.

(10) J. H. O. Varley : Phil. Mag., 45 (1954), 887.

(11) M. Shimoji : J. Phys. Soc. Japan, 14 (1959), 1525.
} 